\title{
METODOLOGIA ATIVA: a importância da pesquisa na formação de professores
}

\author{
Dra. Terezinha RICHARTZ*
}

*Graduada em Sociologia e Política e Pedagogia. Doutora em Ciências Sociais. Professora colaboradora do Mestrado em Letras da Universidade Vale do Rio Verde. Email: terezinha@unincor.edu.br

Recebido em: 15/04/2015 - Aprovado em: 07/06/2015 - Disponibilizado em: 15/07/2015

\begin{abstract}
Resumo: Cada vez mais, as instituições de ensino precisam se preocupar com o perfil do egresso dos seus bancos, em razão do compromisso social e político que possuem com a comunidade. O tipo de metodologia utilizada no processo de ensino-aprendizagem é considerado fundamental na formação do discente e, nesse sentido, a metodologia ativa pode ser um dos modos de encaminhar a formação profissional. Como a metodologia ativa estimula o aluno a problematizar, refletir, escolher, criar, intervir e transformar, uma das maneiras de desenvolver o trabalho pedagógico é organizar o ensino-aprendizagem a partir da pesquisa. Neste artigo, é discutida a experiência que está em vigor no curso de pedagogia de uma instituição de ensino superior do sul de Minas Gerais, o qual estruturou seu projeto político pedagógico a partir da investigação. Os dados apontam que a metodologia ativa personificada na formação pela pesquisa supera a cisão da realidade, ao considerar situações reais do contexto educacional do discente e do grupo social em que a escola está inserida. Desse modo, são desenvolvidas habilidades como autonomia, criatividade, responsabilidade e iniciativa, além das competências que preveem o conhecimento específico da área pedagógica, como visão holística dos problemas, trabalho ético e em grupo, de forma inter e transdisciplinar, buscando o crescimento regional.
\end{abstract}

Palavras-chave: Pedagogia. Formação de professores. Metodologia ativa. Pesquisa-ação. Projeto de pesquisa.

\begin{abstract}
Increasingly,educational institutions need to worry about the profile of the graduate from their banks, due to the social and political commitment they have with the community. The kind of methodology used in the teachinglearning process is considered essential in the formation of the student and in that sense, the active methodology can be one of the ways of directing vocational training. As the active methodology encourages the student to question, reflect, choose, create, act and transform, one of the ways of developing the pedagogical work is to arrange the teachinglearning from the research. In this article, it is discussed the experience that has been in effect in the course of pedagogy from a higher education institution in the south of Minas Gerais, which has structured its pedagogical political project from the study. The data indicate that the active methodology embodied in the formation by research overcomes the split of reality, when considering real situations of the education of the student context and the social group in which the school is located. In this way, skills are developed as autonomy, creativity, responsibility and initiative, in addition to skills which provide the specific knowledge of the pedagogical area, as holistic view of of the problems, ethical and group work, in inter- and transdisciplinary manner, seeking regional growth.
\end{abstract}

Keywords: Pedagogy. Teacher education. Active methodology. Action research. Research project. 


\section{INTRODUÇÃO}

Segundo dados do INEP/MEC, em sua maioria, os cursos de pedagogia no Brasil são oferecidos no período noturno (LEITE; LIMA, 2010). Oriunda de classes sociais mais baixas, parte significativa dos estudantes desses cursos trabalha durante o dia e estuda à noite. Muitos deles chegam à sala de aula sem alimentação adequada, indo diretamente do trabalho para a universidade.

A pergunta inicial que orientou toda a discussão acerca de como construir o projeto pedagógico para esse tipo de clientela foi: como envolver os alunos no processo de ensino-aprendizagem para que de fato "aprender a aprender" passe a ser realidade no curso de pedagogia? Para responder tal indagação, foi analisado o projeto político pedagógico do curso de pedagogia de uma instituição privada de ensino superior do sul do estado de Minas Gerais. Além da análise, foi efetuada uma verificação sobre a disposição das etapas percorridas por discentes e docentes para a realização das suas pesquisas.

$\mathrm{Na}$ atual conjuntura, é necessário coragem para mudar o formato dos cursos de pedagogia e colocar em prática a lei 9394: “a educação superior tem por finalidade incentivar $\mathrm{o}$ trabalho de pesquisa $\mathrm{e}$ investigação científica, visando o desenvolvimento da ciência e da tecnologia e da criação e difusão da cultura, e desse modo, desenvolver o entendimento do homem e do meio em que vive" (BRASIL, Lei 9394/96, art. 41, item III). As instituições particulares de ensino superior, na sua grande maioria, não possuem financiamento público para subsidiar os alunos pesquisadores.

A fim de conhecer melhor os problemas dos alunos - ou entender as dificuldades da comunidade escolar onde o discente está inserido -, pode-se usar a pesquisa como espinha dorsal no processo formativo, buscando-se respostas baseadas em critérios científicos. Assim, é necessário um olhar investigativo, atento a tudo que acontece, muito estudo e reflexão para que a atuação possa ser de fato transformadora.

\section{A PEDAGOGIA ATIVA COMO PROCESSO EDUCATIVO}

As metodologias ativas têm como princípio teórico a autonomia. Autores como Freire (1996) e Demo (1996) asseveram que a autonomia é fundamental no processo pedagógico e a pesquisa é uma das formas de viabilizar o aprendizado e o desenvolvimento da autonomia intelectual e da consciência crítica. Com elas, o aluno constrói seu conhecimento em vez de recebê-lo de forma passiva do professor. $\mathrm{O}$ aluno que possui essas competências pode questionar e intervir na realidade com muito mais propriedade.

Através das metodologias ativas, é possível usar a problematização como 
estratégia de ensino-aprendizagem. Com problemas reais, o discente costuma estar muito mais motivado para examinar, refletir e pode relacionar à sua história o que é investigado, ressignificando suas descobertas. Problematizar facilita o contato com as informações, bem como a produção do conhecimento, objetivando solucionar os impasses e possibilitando o próprio desenvolvimento.

Para Freire (1996), a ação de problematizar enfatiza a práxis, na qual o sujeito busca saídas para intervir na realidade em que vive, e o capacita a transformá-la por sua ação, ao mesmo tempo em que se transforma. Assim, o sujeito identifica novos problemas num processo ininterrupto de buscas e mudanças. Nessa perspectiva, pensamento e ação são indissociáveis. Professores e alunos são convidados a questionar sua própria prática, trazendo para a comunidade em que estão inseridos as questões éticas, sociais e políticas do sistema escolar, contribuindo para a construção da cidadania. Silberman (1996, p. 83) resume os princípios das metodologias ativas:

\footnotetext{
O que eu ouço, eu esqueço;

O que eu ouço e vejo, eu me lembro;

$\mathrm{O}$ que eu ouço, vejo e pergunto ou discuto, eu começo a compreender; $\mathrm{O}$ que eu ouço, vejo, discuto e faço, eu aprendo desenvolvendo conhecimento e habilidade;

$\mathrm{O}$ que eu ensino para alguém, eu domino com maestria (grifos nossos).
}

Nos princípios da metodologia ativa, o aluno domina o conteúdo quando ensina o que sabe. Como o curso de pedagogia objetiva formar professores, os egressos se tornam competentes se tiverem, como alunos, a oportunidade de expor o que aprenderam em momentos de socialização do conhecimento, entre os pares e com os docentes, os quais podem apontar caminhos nas dificuldades. $\mathrm{O}$ papel do professor é o de orientar e mediar o processo de aprendizagem.

Uma vez que existem várias formas de trabalhar com a metodologia ativa, neste artigo, é apresentada a pesquisa enfatizando-se em especial a pesquisa-ação como uma alternativa eficaz para desenvolvimento de habilidades e atitudes, além de aquisição de conhecimento, portanto, do desenvolvimento de competências, pois se opõe a métodos e técnicas que enfatizam a transmissão do conhecimento.

\section{A IMPORTÂNCIA DA PESQUISA- AÇÃO}

Alunos trabalhadores possuem menos tempo para estudar, mas são instigados o tempo todo com questões sem respostas que afloram na sua rotina diária. Tais dificuldades reais são campo profícuo para desenvolvimento nesses alunos da necessidade de pesquisar sempre antes de tomar qualquer decisão.

A maioria das instituições de ensino planeja e implementa o trabalho pedagógico a partir de ideias cristalizadas que impedem a 
organização dos tempos e dos espaços escolares de forma diferente. Por isso é difícil para o corpo docente (re)elaborar um projeto pedagógico que viabilize situações de ensino inovadoras e estabelecer uma proposta educativa distinta, que inclua a pesquisa.Estruturar um projeto pedagógico que tenha como espinha dorsal a pesquisa é uma ação desafiadora. Parte-se do pressuposto de que o professor é, por excelência, um pesquisador ou que pelo menos acredita na pesquisa como elemento formativo. Neste último caso, para que o docente tenha tal perfil profissional, é necessário que, na sua formação, o aluno experimente que é possível ser um professor pesquisador, até mesmo porque a prática pedagógica cotidiana é um terreno fértil de questões que, em geral, não têm respostas definitivas. Como afirma Demo (1996, p. 2):

Educar pela pesquisa tem como condição essencial primeira que o profissional da educação seja pesquisador, ou seja, maneje a pesquisa como princípio científico e educativo e a tenha como atitude cotidiana. Não é o caso de fazer dele um pesquisador 'profissional', sobretudo na educação básica, já que não a cultiva em si, mas como instrumento principal do processo educativo. Não se busca um 'profissional da pesquisa', 'mas um profissional da educação pela pesquisa'. Decorre, pois, a necessidade de mudar a definição do professor como perito em aula, já que a aula que apenas ensina a copiar é absoluta imperícia (grifos nossos).

Não é possível educar pela pesquisa se o professor não estiver convencido da importância dessa metodologia. A prática pedagógica precisa ser arejada pelas descobertas científicas feitas pela ciência, para, assim, dar respostas diferentes aos desafios pedagógicos, políticos e sociais enfrentados pela comunidade escolar. Nesse sentido, tanto o docente do curso de pedagogia como o discente precisam estar envolvidos com a pesquisa.

Acerca da questão, Freire (1996, p. 32) afirma:

Não há ensino sem pesquisa e pesquisa sem ensino. Esses que-fazeres se encontram um no corpo do outro. Enquanto ensino continuo buscando, reprocurando. Ensino porque busco, porque indaguei, porque indago e me indago. Pesquiso para constatar, constatando, intervenho, intervindo educo e me educo. Pesquiso para conhecer o que ainda não conheço e comunicar ou anunciar a novidade.

Os alunos do projeto pedagógico analisado neste artigo são inseridos na pesquisa através de um trabalho interdisciplinar, que começa no terceiro período do curso e envolve os discentes, os docentes e a coordenação do curso de pedagogia. Com o mínimo de conhecimento das disciplinas específicas, uma vez que educar pela pesquisa é considerado o caminho no processo formativo, os alunos começam problematizando a realidade. Nasce daí o problema da pesquisa. Nessa perspectiva, não é necessário que o aluno tenha base teórica para investigar, mas a pesquisa é o caminho para alcançar a base teórica. 
O amadurecimento intelectual do aluno vai aos poucos se manifestando através do envolvimento nas atividades propostas. A angústia inicial, causada pela necessidade de identificar um problema, relevante para si e para a sociedade, se dissipa paulatinamente, graças ao contato direto que o aluno tem com a realidade escolar, parte dele propiciada pelo estágio curricular obrigatório e outra fração, pela experiência que ele já traz da sala de aula. Tal realidade tem tantos problemas para serem investigados que o discente logo percebe a fertilidade do terreno.

O resultado final é que parte significativa dos alunos e dos professores estuda muito, pesquisa, questiona a realidade e ressignifica conceitos, mudando, assim, a prática pedagógica em sala de aula. Nessa modalidade de metodologia ativa, os métodos e as técnicas estimulam a interação entre estudantes e professores, entre estudantes e estudantes, entre estudantes e material didático e outros recursos de aprendizagem.

A pesquisa-ação é um jeito diferente de começar a pesquisa. É a realidade que instiga. É dela que nascem as perguntas. Tal modo de fazer pesquisa tira dos pesquisadores tradicionais - que são muito importantes para o desenvolvimento da ciência - a primazia sobre a investigação.

A pesquisa-ação é um tipo de pesquisa social com base empírica que é concebida e realizada em estreita associação com uma ação ou com a resolução de um problema coletivo e no qual os pesquisadores e os participantes representativos da situação ou do problema estão envolvidos de modo cooperativo ou participativo (THIOLLENT, 2004, p. 14).

O cerne de todo o processo de pesquisa é o questionamento reconstrutivo. A pesquisa se torna atitude cotidiana, desenvolvendo-se um olhar clínico sobre os problemas. Para Demo (1996, p. 5), os pressupostos básicos da proposta de educar pela pesquisa são:

- a convicção de que a educação pela pesquisa é a especificidade mais própria da educação escolar e acadêmica,

- o reconhecimento de que o questionamento reconstrutivo com qualidade formal e política é o cerne do processo de pesquisa,

- a necessidade de fazer da pesquisa atitude cotidiana no professor e no aluno, e

- a definição de educação como processo de formação da competência histórica humana.

Demo (1996) acredita que é impossível sair da condição de objeto, ou seja, de massa de manobra, sem formar consciência crítica dos problemas e com iniciativa própria contestar tal situação. O questionamento deve levar a mudanças. Aí nasce o sujeito que segue vida afora questionando permanentemente a realidade. Nesse sentido, pesquisa e educação coincidem, ainda que uma não possa ser reduzida à outra na totalidade.

Como as instituições de ensino têm dificuldades de alterar o espaço das tradicionais aulas expositivas, o maior desafio é incorporar a aprendizagem ativa no tempo- 
espaço escolar. Mesmo as avaliações de desempenho que devem ser respondidas pelos discentes, professores e coordenadores apontam para a metodologia tradicional, pois as perguntas avaliativas costumam versar, entre outras questões, sobre a capacidade do professor de controlar alunos, sobre o cumprimento do horário em sala de aula e sobre a aplicação dentro do previsto da prova clássica determinada pela direção da instituição, na maioria dos casos, com pontuação definida pelo conselho superior. O uso da biblioteca e do laboratório de informática ou as idas a campo para pesquisa são considerados por muitos contraproducentes.

O plágio nos trabalhos científicos é procedimento recorrente nas instituições de ensino superior. Uma das formas de ser combatido é o investimento em projetos pedagógicos bem estruturados e o compromisso do corpo docente com a orientação, corrigindo e acompanhando permanentemente a produção científica do aluno.

Atualmente, com a revolução da informática (PENIN, 2001), tornam-se necessárias novas formas de organizar a escola e exercer a didática. $O$ saber se apresenta para os sujeitos de forma direta. A tecnologia disponível especialmente por meio da internet possibilita diferentes modos de acesso ao saber, os quais não seguem apenas a uma ordem hierárquica. $\mathrm{O}$ professor passa a ser o mediador de uma trajetória que é construída pelo aluno.

A condição sinequa non para a educação pela pesquisa é que o professor seja pesquisador. Não necessariamente, ele deve ser um profissional da pesquisa, mas como profissional da educação precisa ser um pesquisador. $\mathrm{O}$ ambiente de aprendizagem ativa pressupõe que o professor atue como orientador, supervisor e facilitador do processo de aprendizagem, não apenas como o único detentor do conhecimento já sistematizado.

Sobre isso, Freire (1996, p. 32) assevera:

Fala-se hoje, com insistência, no professor pesquisador. No meu entender o que há de pesquisador no professor não é uma qualidade ou uma forma de ser ou de atuar que se acrescente à de ensinar. Faz parte da natureza da prática docente a indagação, a busca, a pesquisa. O que se precisa é que, em sua formação permanente, o professor se perceba e se assuma, porque professor, como pesquisador. (grifo nosso).

Sendo parte da natureza da prática docente, é fundamental que a pesquisa seja institucionalizada nos cursos de formação de professores como elemento formativo. Quando inseridas no curso de pedagogia as metodologias ativas de ensino-aprendizagem, tendo a pesquisa como fio condutor, alunos e professores se tornam pesquisadores, reflexivos sobre sua práxis e cidadãos ativos, contribuindo para o desenvolvimento da região em que estão inseridos. 


\section{RESULTADOS E DISCUSSÃO}

Os dados citados neste artigo foram retirados do projeto político pedagógico e de projetos correlatos que norteiam a prática da instituição que é objeto do presente estudo.

Os professores do curso de pedagogia analisado são todos convidados a orientar projetos monográficos, assim, seu desafio é permanente, pois existe o questionamento por parte dos alunos e o professor é envolvido no processo, sentindo necessidade de pesquisar e de aprender sempre mais. Não é possível orientar se não se sabe pesquisar. Por isso o objetivo do programa de iniciação científica é iniciar professores e alunos na pesquisa.

O programa de iniciação científica da instituição analisada prevê os seguintes procedimentos:

\footnotetext{
- Acompanhar os alunos nas suas potencialidades e dificuldades acadêmicas.

- Iniciar alunos, e secundariamente também professores, no processo de produção de pesquisa e dos resultados da pesquisa, desde a criação, leitura, levantamento bibliográfico, metodologia, orientação etc.

- Produzir pesquisa de relevância para as pessoas envolvidas, para a instituição e para a comunidade, ou seja, dar ao curso uma dimensão de responsabilidade social através da pesquisa.
}

Com essa prática, as resistências iniciais dos alunos e a noção de que a monografia é um "bicho de sete cabeças", aos poucos, vão se dissipando.

O projeto pedagógico estabelece que:
O currículo de pedagogia, voltado para a formação do pedagogo docente e do pedagogo gestor, deverá ser necessariamente estruturado tendo as atividades de pesquisa e extensão como mediadoras da formação. A pesquisa, como a possibilidade de acesso ao conjunto de conhecimentos produzidos, seus modos de produção, bem como instância de reflexão sobre a realidade.

O aluno escolhe o problema de pesquisa e individualmente desenvolve o tema monográfico. Individualmente porque mesmo estando em diálogo permanente com os colegas, com seu orientador e com os demais professores, a sistematização é feita isoladamente. Não é permitida a entrega de trabalhos em grupo. Mesmo que haja momentos de debate, pesquisa conjunta e reflexão sobre os problemas encontrados, as leituras, os fichamentos e a produção de trabalhos devem ser individualizados para possibilitar a sistematização do conhecimento. No terceiro período, os alunos produzem textos para treinar as técnicas metodológicas. A partir do quarto período, todos os trabalhos desenvolvidos para a elaboração da monografia são confeccionados de forma individual.

Existe na grade curricular uma disciplina que viabiliza a parte metodológica. Nela, o professor acompanha os discentes nas suas dificuldades, para que o rigor científico seja garantido. A ementa da disciplina determina: 
O programa de iniciação científica deve materializar-se no projeto de monografia tendo por objetivo e devendo ser desenvolvido para servir como um eixo de referência para as atividades de cada um dos períodos. Do primeiro contato à conclusão do curso, os rascunhos, projetos e monografia devem constituir um fio em torno do qual as atividades do curso se organizam.

Para materializar a pesquisa, o curso foi assim estruturado:

\begin{abstract}
$3^{\text {o }}$ período - Introdução ao pensamento científico que trabalha a metodologia científica básica.

$4^{\circ}$ período - Elaboração do projeto de pesquisa que prioritariamente deve partir da experiência vivenciada no estágio ou da experiência da atuação política na comunidade. Leitura e fichamento de três obras relativas ao problema elaborado. $5^{\circ}$ período - Leitura e fichamento de mais três obras e produção de um artigo científico, a partir do problema elaborado no $4^{\circ}$ período, utilizando as seis obras lidas.

$6^{\circ}$ período - Elaboração do esboço da monografia. Devem ser incorporadas nesta etapa tudo o que foi produzido nas etapas anteriores, além de incorporar a leitura de mais três obras novas.

$7^{\circ}$ período - Aperfeiçoamento do esboço dos capítulos da monografia redigidos no $6^{\circ}$ período. Leitura do restante das obras necessárias para responder o problema de pesquisa a partir da teoria disponível. Elaboração da redação definitiva da monografia a partir da bibliografia lida. Formatação de acordo com a ABNT e apresentação da monografia para banca.
\end{abstract}

A experiência tem mostrado que essa formatação possibilita que os alunos trabalhem nas suas monografias desde os primeiros períodos do curso. Assim, já no quarto período, definem um problema de pesquisa. Se houver necessidade de ajustes em relação ao projeto, isso acontece em qualquer momento. O importante é que cada aluno, dentro da sua dinâmica, elabora resenhas dos livros lidos e produz pequenos textos em cada período. Os alunos são, portanto, respeitados no seu processo de aprendizado. Como resultado final, a monografia é confeccionada sem sofrimento ou atropelo e, mais do que isso, serve como caminho que, depois, pode ser seguido na vida docente como atitude cotidiana. Quem adquire o gosto pela pesquisa não a faz por obrigação, mas como atitude de vida.

\section{CONCLUSÃO}

Educar pela pesquisa é uma alternativa metodológica bastante interessante. Os resultados desse procedimento apontam para o envolvimento dos alunos com a produção monográfica. A experiência de produzir a monografia a partir da prática pedagógica possibilita que os alunos aprendam a usar a investigação científica como exercício cotidiano. Os problemas que surgem rotineiramente passam a ter novas soluções quando a teoria começa a iluminar a prática. Se a forma como é conduzido o processo de ensino/aprendizagem favorece no aluno a capacidade de ouvir, ver, perguntar, discutir, fazer e ensinar, o caminho seguido é o da aprendizagem ativa.

Sendo uma das possibilidades oferecidas pela metodologia ativa, na educação pela pesquisa, o aluno é o sujeito do processo de aprendizagem. Como as 
habilidades e competências são parte integrante das avaliações do Ministério da Educação, utilizar a pesquisa na formação do futuro docente permite o contato direto com a realidade e a reflexão, à luz da teoria, acerca dos problemas que atingem o grupo social, possibilitando a intervenção e contribuindo para a transformação social.

O conteúdo apreendido pelos discentes nessa metodologia é animador. Os dados do curso pesquisado neste artigo apontam para bons resultados no Enade. As notas nunca foram inferiores a 4 e a avaliação do curso é considerada boa segundo critérios do Ministério da Educação, disponíveis no site do emec.

\section{REFERÊNCIAS}

BRASIL. Senado Federal. Lei de Diretrizes e

Bases da Educação Nacional: nº 9394/96.

Brasília: Senado Federal, 1996.

CYRINO, E. G.; PEREIRA M. L.T.

Trabalhando com estratégias de ensinoaprendizado por descoberta na área da saúde: a problematização e a aprendizagem baseada em problemas. Cad Saúde Pública, [S. 1.], v. 20, n. 3, p. 780-788, 2004.

DEMO, P. Pesquisa: princípio científico e educativo. 2. ed. São Paulo: Cortez, 1991.
FREIRE, P. Pedagogia da autonomia: saberes necessários à prática educativa. 21 . ed. São Paulo: Paz e Terra, 1996. 156 p. (Coleção Leitura)

LEITE, Y. U. F.; LIMA, V. M. M. Cursos de pedagogia no Brasil: o que dizem os dados do INEP/MEC? Ensino Em-Revista, Uberlândia, v.17, n.1, p. 69-93, jan./jun. 2010.

PENIN, S. T. S. Didática e cultura: o ensino comprometido com o social e a contemporaneidade. In: CASTRO, Amélia Domingues de; CARVALHO, Anna Maria Pessoa de. Ensinar a ensinar: didática para a escola fundamental e média. São Paulo: Pioneira Thomson, 2001. Cap. 2, p. 33-52.

THIOLLENT, M. Metodologia da pesquisaação. 13. ed. São Paulo: Cortez, 2004.

SILBERMAN, M. Active learning: 101 strategies do teach any subject. Massachusetts: Allynand Bacon, 1996.

Educar pela pesquisa. Campinas:

Editores Associados, 1996 